\title{
El control abstracto de la constitucionalidad de las leyes en México*
}

\section{Joaquín Brage Camazano}

\section{Introducción}

Mientras algún sector de la doctrina germana' y también más recientemente de nuestra propia doctrina ${ }^{2}$ discute sobre la oportunidad y conveniencia de la supresión (Abschaffung), a secas, del control normativo abstracto de la constitucionalidad, lo cierto y verdad es que prácticamente todos los países que en los últimos años han decidido por razones diversas, y en general al inaugurar un régimen democrático de gobierno introducir un tribunal constitucional, han atribuido a éste, como una de sus más relevantes competencias, la que se refiere al control normativo abstracto de la constitucionalidad, ${ }^{3}$ competencia que bien puede decirse que viene siendo, respecto de los tribunales constitucionales, al menos hasta el día de hoy, verdaderamente emblemática.

$Y$ esto ha sido justamente lo que ha ocurrido en México por virtud de la reforma de diciembre de 1994 a la Constitución de 1917, que da al artículo 105 de la Constitución un nuevo contenido, por virtud del cual se atribuye a la Suprema Corte una competencia para conocer de los procesos iniciados por medio de la acción de inconstitucionalidad, para plantear la cual se legitima a ciertos órganos políticos. Por esta vía se abre la posibilidad, inédita hasta ese momento en México, de un control abstracto de la constitucionalidad de las leyes que se concentra en la Suprema Corte y permite a ésta emitir declaraciones de inconstitucionalidad dotadas de eficacia general. La atribución de esta competencia a la Suprema Corte parece haber sido considerada por la doctrina como el último eslabón de una cadena que ha llevado a que la Suprema Corte se haya convertido en un verdadero tribunal constitucional. ${ }^{4} \mathrm{Y}$, desde luego, sea cual sea la naturaleza de la actual Suprema Corte, no cabe dudar de que la atribución de esta nueva competencia para conocer del control abstracto de la constitucionalidad de las leyes supone un paso muy importante en la progresiva aproximación, material al menos, de la Suprema Corte a los tribunales constitucionales. ${ }^{5} \mathrm{El}$ objeto de las siguientes páginas viene precisamente constituido por el examen de la articulación técnica-en el nuevo artículo 105 constitucional y en la Ley Reglamentaria (o de desarollo) de sus fracciones I y II (en adelante, LR105)- de este nuevo instituto procesal-constitucional mexicano que es la acción de inconstitucionalidad, sin que podamos, sin embargo, entrar aquí en el estudio de la problemática planteada por la inserción de este instituto de control abstracto de la constitucionalidad en el sistema, tradicional en México y mantenido por la reforma de 1994, de control concreto por la vía del amparo, como tampoco en la cuestión de la coordinación de la acción de inconstitucionalidad con las controversias ( $=$ conflictos) constitucionales que versen sobre disposiciones generales con rango de ley.

\section{Legitimación activa}

Se ha seguido en este punto, de una manera estricta, la técnica germana de la legitimación restringida a ciertos órganos políticos (Organklage), que caracteriza al control abstracto de la constitucionalidad tal y como se ha instaurado en media Europa, y que, tal y como Fernández Segado nos recuerda, responde a la necesidad de cierta moderación en el recurso a este mecanismo procesal ${ }^{6}$ En concreto, los órganos (o fracciones de los mismos) que aparecen legitimados en el artículo 105 constitucional para someter una norma a un control abstracto de la constitucionalidad son los siguientes:

1. Minorías parlamentarias. Por un lado, aparecen legitimados el equivalente al treinta y tres por ciento de los integrantes bien de la Cámara de Diputados (apartado a), bien del Senado (apartado b), bien de alguno de los órganos legislativos estatales (apartado d) bien de la Asamblea de Representantes del Distrito Federal (apartado e). Es claro que con esta legitimación se pretende proteger a las minorías parlamentarias. ${ }^{8} \mathrm{Al}$ mismo tiempo que se las instrumentaliza al servicio de la supremacía constitucional,' para cuya defensa una legitimación de este tipo parece ser uno de los cauces más adecuados, $o$ al menos eso parece desprenderse de la expansión que ha tenido en el ámbito comparado. Una legitimación de este tipo implica que las dos partes clásicas del sistema parlamentario (mayoría y oposición) desean establecer una ulterior garantía recíproca. Aquellas partes reconocen (es decir, han convenido históricamente en reconocer) que la búsqueda de la razón no puede hacerse equivaler a la fuerza del número expresada en una votación del Parlamento (que haría, en principio, legítima toda decisión de la mayoría), sino que dicha búsqueda debe confiarse a una sede de juicio externa, que encuentra su fundamento legitimador en la posición super partes del juzgador y en el reconocimiento de una lex superior que tutela y somete a ambas, tanto a la maior como a la minor pars, a la mayoría y a la minoría." A lo cual puede añadirse la eficacia preventiva de una legitimación de este tipo, en cuanto que, como ya Kelsen destacara, la simple amenaza de la interposición del recurso ante el Tribunal Constitucional puede ser, en manos de las minorías, un instrumento propicio para impedir que la mayoría viole inconstitucionalmente sus intereses jurídicamente protegidos y para oponerse, en última instancia, a la dictadura de la mayoría, que no es menos peligrosa para la paz social que la de la minoría, pues, en efecto, el dominio de la minoría sólo es soportable si se ejerce de forma regular, con sujeción estricta al texto constitucional. ${ }^{12}$ 
Ahora bien, la regulación mexicana de esta concreta le gitimación ha de merecer una severa crítica por lo cicatera que resulta, hasta el punto de que sólo de una manera limitada va a poder cumplir la acción de inconstitucionalidad, a través de esta legitimación, la finalidad de depuración del ordenamiento y de protección real de las minorías, al menos en tanto no se produzca un vuelco en la situación política mexicana..$^{13}$

Y ello por resultar en la concreta realidad política mexicana $^{14}$ desmesurada la exigencia de un tercio de los representantes, que debería reducirse a un sexto, al menos, a fin de dotar a esta legitimación de una mínima operatividad, que sin duda redundaría en beneficio de la propia supremacía constitucional. Desde luego, lo que es del todo inaceptable, ${ }^{\text {is }}$ desde nuestro punto de vista, es que la principal fuerza opositora, al menos ella, no pueda por sí sola impugnar la inconstitucionalidad de una ley, sino que requiera el concurso de la segunda fuerza parlamentaria en la oposición, y esto último sólo en la Cámara de Diputados, pues en la Cámara de Senadores ya hemos dicho que ni siquiera el conjunto de todas las fuerzas opositoras unidas puede plantear ante la Suprema Corte la eventual inconstitucionalidad de una norma legal. ${ }^{16}$

2. Procurador General de la República. Se trata claramente de la legitimación más amplia, en cuanto a su ámbito objetivo, de todas las que el artículo 105 de la Constitución contempla, pues puede utilizarse tanto respecto de las leyes federales y los tratados internacionales como respecto de las leyes estatales o del Distrito Federal. La adecuada valoración de esta legitimación exige determinar previamente el estatuto jurídico del Procurador de la República. Pues bien, conforme al artículo 102 de la Constitución, el Procurador General es designado por el Titular del Ejecutivo con la ratificación del Senado o, en sus recesos, de la Comisión Permanente; pero podrá ser removido libremente por el Ejecutivo sin el concurso del Senado. Aunque la utilización del adverbio libremente parece dar a entender que es una remoción que no está sujeta a la concurrencia de causa alguna, lo cierto es que el artículo citado aparecía ya con esa redacción en la Iniciativa del Presidente de la República en que tuvo su origen la reforma constitucional de 1994 que dio al precepto su nueva redacción hoy vigente, y en dicha Iniciativa de Reforma, su autor (esto es, el Presidente de la República) trataba de justificar esa libre destitución en los siguientes términos: se considera necesario que permanezca el régimen de remoción libre por el Ejecutivo, toda vez que, por ser éste el responsable último de velar por la aplicación de la ley en el ámbito administrativo, debe estar facultado para actuar firmemente cuando perciba que la institución se desempeña de manera negligente o indolente en la persecución de los delitos de orden federal. Con ello, en la concepción del autor de la iniciativa de reforma, la remoción libre aparece vinculada a un desempeño negligente o indolente por parte del Procurador en el ejercicio de la que acaso sea su función más emblemática, la persecución de los delitos federales. Teniendo en cuenta que el artículo 102 no sufrió modificación alguna en el Parlamento y nadie discutió en el mismo la interpretación dada por el Presidente en la Ini- ciativa de reforma, cabe interpretar que la remoción libre en realidad presupone un ejercicio negligente o indolente por parte del Procurador de sus funciones, especialmente de las que se refieren a la persecución de los delitos federales.

De no admitirse esta interpretación, y sostener la tesis de la dependencia absoluta del Procurador General del Ejecutivo (en cuanto que éste podría destituirlo sin causa alguna, de manera absolutamente libre), la legitimación aquí contemplada quedaría en muy buena medida desvirtuada, tanto respecto de las leyes federales como respecto de los Tratados Internacionales como incluso, en cierta medida al menos, respecto de las leyes estatales. Y ello porque, en cuanto a las primeras, su promulgación corresponde siempre al Presidente de la República, quien tiene además respecto de ellas una facultad de veto, aparte de que el Presidente de la República viene disfrutando desde hace siete décadas de una cómoda mayoría parlamentaria, con lo cual no se producen discrepancias de fondo entre el Presidente y las Cámaras, siendo frecuente además que las leyes tengan su origen en la iniciativa presidencial. De este modo, la impugnación de unas leyes que, en último término, y al menos en sus aspectos básicos, reflejan la voluntad política del Presidente de la República, por parte de quien depende absolutamente en su continuidad en el cargo del propio Presidente no parece en modo alguno probable. Todavía menos probable y coherente resultaría la utilización de la legitimación que contemplamos respecto de los Tratados Internacionales, cuya celebración es facultad del Presidente de la República. La impugnación por el Procurador General de las leyes federales, y más todavía de los tratados internacionales, sería en realidad, y en la práctica, un enfrentamiento directo con el Presidente de la República. Y en el caso de las leyes estatales, la legitimación del Procurador General, si se sostiene su dependencia absoluta respecto del Presidente de la República, sólo sería posible respecto de las leyes de aquellos Estados en que el partido del Presidente no tuviese la mayoría, aparte de que, desde luego, el Procurador General no podría en ningún caso funcionar como instancia objetiva respecto de la impugnación de las leyes de los Estados.

Todo ello no hace sino reforzar la necesidad de una interpretación como la arriba sostenida, a partir del texto del autor de la Iniciativa de Reforma, sobre la independencia, al menos relativa, del Procurador General frente al Ejecutivo, a fin precisamente de que la legitimación estudiada tenga un mínimo sentido y operatividad. ${ }^{17}$

3. Partidos políticos. En tercer lugar, pueden interponer la acción de inconstitucionalidad frente a leyes electorales, federales o locales, los partidos políticos con registro ante el Instituto Federal Electoral, así como los partidos políticos con registro estatal, aunque estos últimos exclusivamente en contra de leyes electorales expedidas por el órgano legislativo del Estado que les otorgó el registro.

Esta legitimación específica respecto de las leyes electorales resulta un tanto extraña, pero está totalmente justificada y será sin duda positiva en la realidad política mexicana, por la peculiar historia de este país nortea- 
mericano en el que un partido, como es el PRI, ha controlado durante varias décadas todos los resortes de poder, tanto federales como estatales y municipales, y por supuesto también los procedimientos electorales. La especial importancia que en todo proceso democratizador, como el que está viviendo México desde hace algunos años, tiene el procedimiento electoral ${ }^{18}$ se acentúa si cabe en una realidad política como la mexicana en la que bien puede decirse que el control de la constitucionalidad y hasta de la legalidad de las leyes electorales era hasta hace bien poco un verdadero tabú jurídico, con el que se ha roto de manera decidida, aunque todavía incompleta, a través de la reforma constitucional de 1994. Y resulta claro que son los partidos políticos los principales interesados en el respeto de las normas constitucionales atinentes a la materia electoral, aparte ya de su alta misión constitucional (artículo 122 de la Constitución), siendo todo ello lo que explica esta legitimación específica, pero concurrente, en favor de los partidos políticos..$^{19}$

No se exige aquí -y ello marca una diferencia sustancial respecto de la legitimación de las minorías parlamentarias- haber obtenido una determinada representación parlamentaria ${ }^{20}$ sino que basta con que el partido político impugnante de la ley esté registrado, ${ }^{21}$ bien a nivel nacional (respecto de las leyes electorales federales y locales), bien a nivel estatal (respecto de las leyes electorales del Estado en que se haya registrado).

Por último, debe decirse que los partidos políticos que hagan uso de su legitimación habrán de hacerlo a través de sus dirigencias, por así determinarlo expresamente la Constitución. Cuando sean partidos con registro a nivel nacional (en el Instituto Federal Electoral), la pertinente decisión de interposición de la acción habrá de adoptarse por las dirigencias nacionales pues así lo determina también el nuevo apartado f) del artículo 105.II y ello incluso para el caso de que la ley que se impugne sea estatal y no nacional, pues el elemento decisivo que se tiene en cuenta es el ámbito del propio partido y no el de la ley impugnada. La solución es, obviamente, distinta cuando el partido político tenga registro estatal, pues en tal supuesto dice el precepto constitucional que los partidos ejercen esta legitimación a través de sus dirigencias, dirigencias que son las de ámbito estatal y sólo, naturalmente, respecto de leyes del Estado que les otorgó el correspondiente registro. ${ }^{22}$

\section{Objeto}

Aunque el artículo 105.II de la Constitución establezca en principio que la acción de inconstitucionalidad procede contra normas generales, lo cierto es que el propio artículo especifica, más adelante, cuáles son exacta y exclusivamente las normas generales controlables por esta vía y lo hace de una forma restrictiva y conforme a un taxativo sistema de numerus clausus. De ello se deduce que pueden ser impugnadas por medio de la acción de inconstitucionalidad únicamente las siguientes normas generales: a) las leyes; b) los tratados internacionales.

Por lo que a las primeras atañe, puede tratarse de leyes tanto de la Federación como de los Estados como también del Distrito Federal, aunque, eso sí, ha de tratarse en todo caso de leyes aprobadas, promulgadas y publicadas en la fecha de entrada en vigor de la LR105, pues respecto de las leyes anteriores a tal fecha no se admite siquiera un régimen transitorio para su impugnación. ${ }^{23}$

Entre dichas leyes se excluyeron inicialmente, por la reforma constitucional de 1994, las referidas a la materia electoral, ámbito éste que quedaba así exento de control de constitucionalidad en una regulación que no sólo carecía de base lógica sino que suponía, en realidad, dejar excluidas de todo control justamente a las reglas del juego democrático; resultaba además completamente incongruente con la progresiva juridificación y jurisdiccionalización de la materia electoral que venía produciéndose en México en los últimos años; y, en fin, no concordaba con el control de constitucionalidad que sobre dichas leyes se verificaba con toda normalidad en los distintos ejemplos que el Derecho Comparado nos mostraba. Todo ello, junto a la crítica doctrinal generalizada en los primeros estudios sobre la acción de inconstitucionalidad, fue sin duda lo que llevó al legislador de reforma constitucional a volver bien pronto sobre sus propios pasos, rectificando de este modo, a través de la reforma a la Constitución de agosto de 1996, esa exclusión inicial de todo control a través de la acción de inconstitucionalidad de la materia electoral. Y si bien las leyes electorales están ahora sujetas a control por medio de la acción de inconstitucionalidad, rige respecto de ellas una serie de especialidades: a) la legitimación específica, ya vista, de los partidos políticos, concurrente con la genérica para todas las leyes; b) su constitucionalidad sólo puede controlarse o examinarse jurisdiccionalmente a través de la acción de inconstitucionalidad, no siendo posible, en particular, hacerlo a través del amparo contra leyes ni a través de las controversias constitucionales, lo que no es más que un residuo de los anteriores recelos hacia el control de constitucionalidad de estas leyes que no parece encontrar una acabada justificación; c) especialidades procedimentales, a que luego nos referiremos, destinadas a imprimir una particular fugacidad al proceso sobre la constitucionalidad de las leyes electorales, dada la especifidad de este tipo de leyes.

Entre las leyes sujetas a control ha de incluirse también, naturalmente, la ley orgánica, aludida por el artículo 70 constitucional (en su redacción tras la reforma de 1977), relativa a la regulación de las formas y procedimientos para la agrupación de los diputados, según su afiliación de partido, a efecto de garantizar la libre expresión de las corrientes ideológicas representadas, aunque parecen no estar, en cambio, sujetos a este control los reglamentos parlamentarios que pueden aprobar cada una de las Cámaras del Congreso de la Unión, sin intervención de la otra, para su propio gobierno interior.

En cuanto a las reformas constitucionales, es preciso distinguir, en primer término, entre las reformas a las Constituciones de los Estados y las reformas a la Constitución Federal. Por lo que a las primeras se refiere, están indudablemente sujetas a control de constitucionalidad por esta vía procesal, control que, en cualquier caso, vendrá referido a la compatibilidad de la reforma a la Constitución estatal con el texto de la Constitución Federal, ${ }^{24}$ no con la propia Constitución local. 
En cuanto a las reformas a la Constitución Federal, conviene diferenciar entre el control formal y el control material de la constitucionalidad. Un control de carácter sustancial de estas reformas sólo será admisible en la medida en que se admita la existencia, en el Derecho Constitucional mexicano, de límites inmanentes o implícitos ${ }^{25}$ a la reforma constitucional, en cuanto que es claro que la Constitución mexicana de 1917 no conoce cláusula alguna de intangibilidad, es decir, no contiene ningún límite material expreso a su propia reforma. La existencia de esos límites inmanentes o, sobre todo, implícitos, así como su exacta delimitación, es discutida en la doctrina mexicana $a^{26}$ y, sólo si se admitiesen, se haría posible un control sustancial o material de la constitucionalidad de las reformas a la Constitución federal, que consistiría en enjuiciar si la reforma en cuestión ha respetado precisamente esos límites implícitos o inmanentes. ${ }^{27}$

La cuestión se plantea en otros términos respecto del control formal o procedimental de la constitucionalidad de las reformas a la Constitución federal, control que en este caso no consistiría en determinar, por contraste, si la reforma en cuestión contradice determinados límites sustantivos, sino simplemente si se ha respetado el procedimiento establecido por la propia Constitución para su reforma, procedimiento que en México es, en concreto, el establecido en el artículo 135 de la Constitución de $1917 .{ }^{28}$ Pues bien, en la doctrina mexicana varios autores han sostenido que no es posible este control ${ }^{29}$ de constitucionalidad de las reformas a la Constitución Federal por medio de la nueva acción de inconstitucionalidad y ello, a juicio de Arteaga Nava, porque una vez que concluye el proceso legislativo, forman parte integrante de la Constitución a pesar de que, como se ha dicho, son obra del Congreso de la Unión. ${ }^{30}$

Dicha postura no nos parece en modo alguno suscribible. Y es que no cabe alegar que, una vez que se aprueben por el Congreso de la Unión, dichas reformas forman parte integrante de la Constitución. Tal argumento está viciado de origen, pues precisamente lo que se está discutiendo es eso: si la reforma constitucional ha cumplido los requisitos que el constituyente originario ha querido que se respetaran para, de ser así, y sólo en la medida en que así fuera, considerar a esas leyes como parte integrante de la Constitución. Pero si esos requisitos no se cumplen, es obvio que no se ha respetado la voluntad constitucional, y la pretendida reforma no puede tener validez, precisamente porque no es, ni se presenta como una nueva Constitución, aprobada por un poder constituyente originario libre y soberano, sino como una simple reforma, obra del poder constituyente constituido. $Y$ este último, justamente en cuanto que constituido, está sometido a la voluntad más fuerte del poder constituyente originario y a las reglas por éste establecidas para la reforma de su propia obra, que es la Constitución. La naturaleza indudablemente legislativa, en sentido material y formal, de las reformas constitucionales, ${ }^{31}$ por más que nos hallemos ante una ley sui generis, ha de llevar por ello, sin mayores obstáculos, a admitir la posibilidad de un control formal de la constitucionalidad de las reformas a la Constitución.

Por otro lado, y con relación también a este mismo tema, cabe señalar, ya desde una perspectiva más general, que de nada serviría reconocer la supremacía de todas y cada una de las normas constitucionales materiales, si después se permite que la Constitución sea modificada (en realidad, vulnerada) por mecanismos que no son los previstos constitucionalmente, modificaciones que podrían libremente afectar a cualesquiera disposiciones de la Constitución sin que hubiese forma de controlar la constitucionalidad misma de la reforma. Salvo que partamos de la concepción de la Constitución como una hoja de papel sin más valor o como mero programa, y no como una auténtica norma jurídica, es claro que allá donde exista un control de constitucionalidad auténtico, éste habrá de extenderse también a las reformas constitucionales pues, de lo contrario, habremos introducido, valga la expresión, un verdadero caballo de Troya en el campo de la supremacía constitucional, rebajando la rigidez constitucional poco menos que a pura retórica legal. Como De Vega ha sostenido, con todo atino, en un conocido estudio: la problemática de la reforma [...] quedaría reducida a una mera disquisición doctrinal, más propia de la metafísica política que de la teoría del Estado constitucional, si no existieran unos controles a cuyo través se asegurara efectivamente su actuación, se garantizara su procedimiento y se fijaran sus límites..$^{32}$

Pero si, como hemos visto, las leyes electorales o las leyes de reforma constitucional están sujetas, precisamente por su naturaleza legislativa, a control por la vía iniciada por la acción de inconstitucionalidad, no lo están en cambio ni los reglamentos administrativos, sean heterónomos o autónomos (o independientes) ${ }_{,}^{33}$ ni tampoco siquiera las disposiciones, normativas con fuerza de ley que, por delegación extraordinaria y excepcional del Congreso de la Unión, puede aprobar el Ejecutivo en las dos hipótesis contempladas en el artículo 49 de la Constitución, por relación con los artículos 29 (situaciones de emergencia: casos de invasión, perturbación grave de la paz pública o grave peligro o conflicto para la sociedad) y 131 (algunos aspectos relacionados con el comercio exterior, la economía del país y la estabilidad de la producción nacional) del mismo texto legal, aunque sí pueden ser objeto de control de su constitucionalidad por esta vía las prevenciones generales del Decreto de suspensión de garantías a que se refiere el artículo 29 cuando las apruebe el Congreso (pero no la Comisión Permanente), así como la aprobación (o rechazo) por el Congreso del uso que haga el Ejecutivo de la facultad a que se refiere el propio artículo 131 en su parte final ${ }^{34}$ Resultan también excluidas del control a través de la acción de inconstitucionalidad las normas de valor legislativo que el propio Ejecutivo puede dictar en el específico supuesto del artículo 27 constitucional, en que se concede al Presidente de la República, directamente y no por delegación del Congreso, facultad legislativa para reglamentar la extracción y utilización de las aguas del subsuelo que pueden ser libremente alumbradas mediante obras artificiales por el dueño del terreno donde broten, así como para establecer zonas vedadas respecto de dichas aguas y de las de propiedad nacional. Quedan asimismo excluidas, en fin, las normas con fuerza de ley que los gobernadores de los Estados puedan emitir en ejercicio de las facultades extraordinarias que les hayan podido ser otorgadas a estos efectos por las legislaturas.

Por último, es preciso decir algo respecto de los tratados internacionales como normas sujetas expresamente al control de la constitucionalidad por la vía que estamos estudiando. Por lo pronto, es de lamentar que no se haya previsto, específicamente respecto de ellos, un control de la 
constitucionalidad de carácter previo, como se ha hecho, entre otros países, en España, Alemania, Francia, Portugal, Colombia, Costa Rica, Bolivia, Eslovenia, o Andorra. ${ }^{35} \mathrm{Y}$ ello se ha hecho en estos países, es de suponer, a la luz fundamentalmente del artículo artículo 26 de la Convención de Viena sobre el Derecho de los Tratados, de 23 de mayo de 1969 que, después de establecer que todo tratado en vigor obliga a las partes y debe ser cumplido por ellas de buena $f e$, contempla expresamente la posibilidad de contradicción del tratado con las normas internas del país de que se trate, y resuelve la cuestión de manera tajante en favor de la primacía incondicional de los Tratados, en cuanto que ninguna de las partes podrá invocar las disposiciones de Derecho interno como justificación del incumplimiento de un Tratado

De ello se desprende que, para los países adheridos a la Convención de Viena citada y entre ellos se cuenta México (que la ratificó en 1974), cualquier Tratado que celebren es vinculante en términos de Derecho Internacional, incluso en el caso de que sea contrario a la Constitución nacional y así lo declare su Tribunal Constitucional o el órgano de la constitucionalidad de que se trate, pues no es admisible la invocación de disposiciones de Derecho interno y entre ellas se encuentra la propia Constitución, obvio es decirlo, lo que por lo demás ha venido confirmado por la jurisprudencia internacional, tanto del Tribunal Permanente de Justicia Internacional como del Tribunal Internacional de Justicia o de la Corte Interamericana de Derechos Humanos. ${ }^{36}$

Precisamente por todo ello, y para tratar de prevenir en cuanto sea posible la responsabilidad internacional del Estado, en los sistemas más avanzados de justicia constitucional se prevé, de manera específica para las normas convencionales internacionales, un control previo de la constitucionalidad, que en ocasiones concurre con otro control posterior y que permite evitar muchos de los inconvenientes que, de otro modo, pueden derivarse de un control exclusivamente a posteriori de la constitucionalidad de las normas internacionales, y esto es lo que, a nuestro juicio, debió haberse hecho en México.

Tampoco nos parece admisible la distinción que algún autor ha sugerido que podía existir entre tratados y convenios internacionales, afirmándose que los segundos quedarían excluidos de control por medio de la acción de inconstitucionalidad. Tal distinción carece, a nuestro modo de ver, de todo apoyo no sólo constitucional y legal, sino también en el propio Derecho Internacional. ${ }^{37}$

\section{Procedimiento}

El procedimiento ${ }^{38}$ se inicia con la recepción de la demanda, designando a continuación el Presidente de la Suprema Corte de Justicia de la Nación, según el turno que corresponda, a un ministro instructor a fin de que ponga el proceso en estado de resolución (artículo 24 LR105). Corresponderá al ministro instructor, por su parte, examinar el escrito de la demanda a fin de desecharla de plano él mismo si encontrare motivo manifiesto e indudable de improcedencia (artículo 25 LR105).

Si el ministro instructor no aprecia ninguna causa de improcedencia, pero encuentra que el escrito de demanda es oscuro o irregular, deberá entonces prevenir al demandante, o a sus representantes comunes, para que hagan las aclara- ciones que correspondan dentro del plazo de cinco días, plazo que se reduce a los tres días en caso de impugnación de leyes electorales. Transcurrido este plazo, el ministro instructor habrá de dar vista a los órganos legislativos que hubieren emitido la norma, así como al órgano ejecutivo que la hubiere promulgado, a fin de que, dentro del plazo de quince días (seis, para leyes electorales), rindan un informe que contenga las razones y fundamentos tendentes a sostener la validez de la norma general impugnada o la improcedencia de la acción de inconstitucionalidad. Cuando la norma impugnada sea una ley aprobada por el Congreso de la Unión, el mentado informe se rendirá por separado por ambas Cámaras.

Salvo en caso de que la acción hubiera sido ejercitada por el propio Procurador General de la República, el ministro instructor habrá de darle vista con el escrito y los informes citados, a efecto de que, hasta antes de la citación para la sentencia, formule el pedimento que corresponda (artículo 66 LR105). Presentados los informes, o transcurrido, en todo caso, el plazo para su presentación, el ministro instructor pondrá los autos a la vista de las partes, a fin de que dentro del plazo de cinco días (o dos, cuando se trate de materia electoral), formulen alegatos (artículo 67).

En todo momento, y hasta antes de dictarse sentencia, podrá el ministro instructor solicitar a las partes o a quien juzgue conveniente, todos aquellos elementos que a su juicio resulten necesarios para la mejor solución del asunto (artículo 68 LR105) y, tratándose de la impugnación de una ley electoral, podrá solicitar opinión a la Sala superior del Tribunal Electoral del Poder Judicial de la Federación.

Una vez agotado el procedimiento, el ministro instructor propondrá al Pleno de la Suprema Corte de Justicia de la Nación el proyecto de sentencia para la resolución definitiva del asunto planteado (artículo 68 LR105). Y cuando la ley impugnada sea de carácter electoral, el proyecto de sentencia deberá ser sometido al Pleno dentro de los cinco días siguientes a aquel en que se haya agotado el procedimiento, debiéndose dictar el fallo por el Pleno a más tardar en un plazo de cinco días, contados a partir de aquel en que el ministro instructor haya presentado su proyecto.

\section{La sentencia}

\section{a. Contenido preceptivo de la sentencia}

La propia Ley reglamentaria establece cuál ha de ser el contenido de las sentencias, por referencia a lo regulado respecto de las sentencias dictadas con motivo de controversias constitucionales. Y con arreglo al artículo 41, la sentencia deberá contener: a) La fijación breve y precisa de las normas generales impugnadas; b) Los preceptos que la fundamenten; c) Las consideraciones que sustenten su sentido, así como los preceptos que en su caso se estimaren violados; $; 9$ d) Los alcances y efectos de la sentencia; ${ }^{40}$ e) los puntos resolutivos que decreten el sobreseimiento, o declaren la validez o invalidez de las normas generales.

Las sentencias se publicarán íntegramente, y de manera conjunta con los votos particulares emitidos, en el Semanario Judicial y, cuando sean estimatorias, también en el Diario Oficial de la Federación y, en su caso, en el órgano (diario) oficial en que la ley impugnada se hubiere publicado. 


\section{b. Mayoría requerida para la declaración de inconstitucionalidad}

La propia Constitución exige, para que la sentencia pueda declarar la inconstitucionalidad con efectos generales, que dicha declaración aparezca respaldada por un mínimo de ocho ministros. Ello supone en la práctica, para el supuesto de que el pleno se haya constituido con sólo ocho de los once ministros -hipótesis que resulta posible por cuanto el quórum para que el pleno quede válidamente constituido es justamente de ocho ministros-, una exigencia nada menos que de unanimidad. Y aún en el mejor de los casos, esto es, si estuvieren presentes los once ministros que integran el pleno, será precisa una mayoría reforzada de un 72 por ciento (prácticamente las tres cuartas partes de los magistrados) para que pueda prosperar una declaración de inconstitucionalidad o, dicho de otro modo, bastará con que cuatro ministros se opongan a la declaración de inconstitucionalidad para que ésta, pese a aparecer amparada por siete ministros, no pueda tener lugar. Si no estuvieren presentes los $11 \mathrm{mi}-$ nistros sino sólo 10,9 u 8 de ellos, bastaría la oposición, respectivamente, de 3,2 o incluso 1 solo de ellos, para que la declaración de inconstitucionalidad auspiciada por otros 7 de ellos no prospere. ${ }^{41}$

Esta exigencia de mayoría reforzada, superior a la mayoría simple por la que razonablemente ha de resolver un órgano jurisdiccional colegiado, carece de todo sentido y supone una extrapolación inadmisible de las reglas del procedimiento parlamentario al proceso judicial, pues, como con todo atino ha señalado Kirchhof, la Jurisdicción [a diferencia del legislador] decide no por autoridad de la mayoría, sino que se inviste de la autoridad de lo justo..$^{42}$ Y no vale, para justificar esta mayoria reforzada exigida, aludir a la presunción de constitucionalidad de las leyes. Esta presunción puede y debe jugar su papel en otros ámbitos o momentos, pero no, desde luego, en lo relativo a la mayoría requerida para la adopción por el órgano competente de una resolución que declare la inconstitucionalidad de una ley, lo que resulta fácil de comprender si se piensa que el órgano competente para adoptar una decisión de este tipo no es un órgano político sino judicial como también lo son sus decisiones y no sólo formalmente, sino también y sobre todo materialmente, en cuanto a los criterios de fondo en que se basan: la sentencia se presenta como fruto del raciocinio jurídico y resultado, no de una conformación de voluntades diversas, sino solamente de interpretaciones (jurídicas y controlables racionalmente) diferentes, y en cualquier caso siempre debidamente fundadas, del texto de la Constitución, lo cual es completamente distinto. El juego que lícitamente pueden tener las mayorías reforzadas en el ámbito parlamentario, y $\tan$ solo limitadamente, no es admisible en el ámbito jurisdiccional o de la justicia, ni siquiera cuando se trata de adoptar decisiones de tal gravedad.

Por otra parte, si lo que se pretendió con esta regulación fue evitar la politización de la Suprema Corte, cabe señalar que se ha errado el camino completamente, pues resulta obvio que el voto favorable a la declaración de inconstitucionalidad de una ley de la mayoría simple (o incluso más) de los ministros, aunque no afecte a la inconstitucionalidad de la ley, desde luego no puede dejar de afectar a su legitimidad y esta deslegitimación de la ley en cuestión sólo servirá para enconar, políticamente hablando, una cuestión que hasta ese momento se había mantenido en cierto reposo. Precisamente por ello es particularmente necesario que los ministros busquen por todos los medios un acuerdo de sus diversas posiciones a fin de evitar a toda costa resoluciones en que una mayoría de los ministros se pronuncia a favor de la inconstitucionalidad, a pesar de lo cual ésta no llega a surtir efectos jurídicos por no alcanzarse en el seno del tribunal la mayoría reforzada exigida para ello. Por la misma razón deberá evitarse a toda costa la constitución del pleno sin alguno de sus miembros. La limitada experiencia de la acción de inconstitucionalidad es, en este sentido, positiva.

Para los supuestos en que no se alcance la mayoría de ocho ministros, se prevé por la Ley Reglamentaria que el Pleno desestimará la acción ejercitada y ordenará el archivo del asunto. Quizás podría haberse establecido aquí, como mal menor, que el voto favorable a la declaración de inconstitucionalidad de seis o siete ministros tendría el valor de recomendación al órgano legislativo que expidió la norma de que se trate pues, como Fix Fierro señala, aunque no hay certeza de que ello fuera apropiado para la autoridad de la Corte, al menos se traduciría en una presión bastante fuerte para cambiar una norma inconstitucional. ${ }^{43}$

\section{c. Efectos de la asistencia}

Las sentencias se benefician del valor de cosa juzgada, es decir, no son susceptibles de recurso alguno (artículo 51 LR105) y se imponen a todos los poderes públicos y autoridades (artículo 43 LR105). Además, la Suprema Corte no puede volver a conocer de la constitucionalidad de esas mismas normas (identidad de objeto) cuando los conceptos de invalidez alegados sean los mismos (identidad de causa), por ser ésa una causa legal de improcedencia.

Se plantea también la cuestión de si la autoridad de cosa juzgada vincula a la propia Suprema Corte en cuanto a la doctrina formulada y la interpretación por ella sostenida y aquí hay que entender que la Suprema Corte no está absolutamente "atada" por sus decisiones anteriores sino que, puesto que la Constitución no es una fórmula matemática ni puede tampoco ser un texto muerto, puede el alto tribunal rectificar criterios anteriores, ${ }^{45}$ lo que en cualquier caso habrá de hacerse sólo en ocasiones contadas, con prudencia y, de manera particular, con una fundamentación especialmente intensa y, por supuesto, siempre de manera expresa, nunca implícita.

Las sentencias estimatorias de la inconstitucionalidad, que han de aparecer respaldadas por al menos ocho ministros, producen efectos erga omnes. Esta eficacia general, que supone, en suma, la expulsión pura y simple del ordenamiento jurídico de la norma enjuiciada, constituye una absoluta novedad en el sistema mexicano de justicia constitucional pues, hasta la reforma de 1994, por medio del amparo contra leyes podía controlarse la constitucionalidad de éstas, pero en virtud de la conocida como fórmula Otero, la eventual declaración de inconstitucionalidad que pudiera obtenerse por parte de cualquier juez o tribunal federal tenía siempre una limitada eficacia inter partes et in casu, incluso cuando era la propia Suprema Corte la que reiteradamente estimaba la inconstitucionalidad de la ley. Por ello ha podido Fix Fierro decir que con la eficacia general que se atribuye ahora a las sentencias estimatorias dictadas con motivo de las acciones de inconstitucionalidad, se rompe una 
barrera, psicológica se diría, construida alrededor de la famosa 'fórmula Otero' en el juicio de amparo. ${ }^{46}$

La eventual sentencia estimatoria, aparte de la mencionada eficacia general en cuanto a los destinatarios tiene una eficacia en el tiempo no retroactiva, en lo que es la solución general en el ámbito latinoamericano (Panamá, Brasil, Colombia, Guatemala, Bolivia, Venezuela, Perú y Ecuador). El artículo 105 constitucional aunque prohíbe los efectos retroactivos, no establece el dies a quo a partir del cual habrá de surtir efectos la sentencia, lo que el legislador ordinario ha aprovechado para establecer que las sentencias producirán sus efectos a partir de la fecha que determine la Suprema Corte de Justicia (artículo 45 LR105), en una regulación cercana a la del Wartefrist o plazo de espera austriaco, pero sin que se fije un plazo máximo a la prórroga jurisprudencial, como sí ocurre en Austria, donde la Constitución prevé un plazo, que en la actualidad, y tras la reforma constitucional de 1992, es de 18 meses. Y tampoco se prevé, como sí se hace en Austria, la posibilidad, siquiera excepcional, de eficacia retroactiva de la sentencia, salvo por lo que respecta a la materia penal, en la que, conforme al propio artículo 105 de la Constitución, regirán los principios generales y disposiciones legales aplicables en esta materia (retroactividad de la disposición penal más favorable).

\section{Terminación anormal del proceso}

El proceso iniciado por la acción de inconstitucionalidad terminará normalmente con una sentencia que resuelva sobre las pretensiones de fondo planteadas en la demanda, pero cabe también la posibilidad de una terminación del proceso anormal o excepcional por la que la Suprema Corte no entra en el fondo del asunto. En este sentido, debe destacarse que la previsión del artículo 65 LR105, según el cual podrá (en realidad, deberá) el ministro instructor en las acciones (procesos, más bien) de inconstitucionalidad aplicar las causas de improcedencia y sobreseimiento de los artículos 19 y 20.

Debe señalarse que, dado que la apreciación de esta improcedencia corresponde exclusivamente al ministro instructor, se contempla en la propia ley una garantía por la que los demás miembros del órgano colegiado se corresponsabilizan de su decisión o, por el contrario, la corrigen o rectifican: cabrá recurso de reclamación contra los autos o resoluciones que admitan o desechen una demanda, su contestación o sus respectivas implicaciones (artículo 51.I LR105).

En cuanto a las causas de improcedencia ${ }^{47}$ y las causas de sobreseimiento, ${ }^{48}$ se contemplan, respectivamente, en los artículos 19 y 20 LR105. Por lo que a las primeras se refiere, conviene subrayar cómo el propio artículo 19, en su último párrafo, establece que en todo caso, las causas de improcedencia deberán examinarse de oficio y el artículo 25 LR105, por su parte, preceptúa que una vez recibida la demanda y designado, según el turno que corresponda, un ministro instructor, deberá éste, ante todo, examinar el escrito de la demanda y si encontrare motivo manifiesto e indudable de improcedencia, la desechará de plano. ${ }^{49}$
Notas
* Este trabajo se publicó originariamente en la Revista de Estudios Políticos, editada por el Centro de Estudios Políticos y Constitucionales, Madrid (España), número 105 (1999), pág. 211-232.

1. Véase, por ejemplo, hace ya más de una década, el sucinto análisis de Christine Landfried sobre la cuestión de la derogación o supresión del control normativo abstracto: Bundesverfassungsgericht und Gesetzgeber, Nomos, Baden-Baden, 1984, págs. 175 y ss. Más recientemente, Hesse ha subrayado cómo el control abstracto se ha evidenciado al paso de los años como cada vez más problemático [...] Y ello nos fuerza a plantearnos, ¿tiene este procedimiento realmente sentido?. Konrad Hesse, Evolución histórica y configuración de la Justicia Constitucional en Alemania, en Antonio López Pina (ed.), División de poderes e interpretación constitucional. Hacia una teoría de la praxis constitucional, Tecnos, Madrid, 1987, pág. 51.

2. Probablemente haya sido Francisco Rubio Llorente el primero, entre nosotros, en referirse explícitamente a la cuestión y, aunque sin llegar a plantear abiertamente la supresión del recurso de inconstitucionalidad, sí manifiesta hacia el mismo su mayor antipatía por la perturbación que implica para el funcionamiento de la democracia parlamentaria (que excede con mucho de los beneficios que de él cabe esperar), así como por su utilidad vivamente discutida, juzgando su introducción una expresión de la desmesura teutónica y que con su supresión los tribunales constitucionales tienen poco que perder y tendrían muchísimo que ganar. Véase, al respecto, su intervención en la discusión de la ponencia de Javier Jiménez Campo, Los procedimientos de declaración de inconstitucionalidad, en el colectivo Los procesos constitucionales. Segundo Simposio de Derecho Constitucional (Sevilla, 27 y 28 de septiembre de 1991), Centro de Estudios Constitucionales, Colección "Cuadernos y Debates", $N^{\circ} 41$, Madrid, 1992, pág. 45; íd., Tendencias actuales de la jurisdicción constitucional en Europa, en Manuel Fraga.Homenaje académico, tomo II, Fundación Cánovas del Castillo, Madrid, 1997, pág. 1429, donde reafirma su 
Notas postura. Un posicionamiento contrapuesto, entre la literatura más reciente, puede verse en Francisco Fernández Segado, La jurisdicción constitucional en España, en el colectivo Francisco Fernández Segado y Domingo García Belaunde, La jurisdicción constitucional en Iberoamérica, Dykinson/Ediciones Jurídicas Lima/E.Esteva/Editorial Jurídica Venezolana, Madrid, 1997, quien entiende que nuestro recurso de inconstitucionalidad tiene una operatividad funcional que debe ser preservada (pág. 634).

3. Es el caso, entre otros países, de Bolivia, Colombia, Costa Rica [Sala de lo Constitucional], Ecuador, Guatemala, Perú, Eslovenia, Eslovaquia, Polonia, Bulgaria o Lituania.

4. Jorge Carpizo, Reformas constitucionales al Poder Judicial federal y a la jurisdicción constitucional del 31 de diciembre de 1994, Boletín Mexicano de Derecho Comparado, Universidad Nacional Autónoma de México, Nueva Serie, año XXVII, No 83, mayo-agosto, 1995, pág. 808; Salvador Valencia Carmona, Derecho Constitucional mexicano a fin de siglo, Porrúa, México, 1995, pág. 416 ss; Castro y Castro, Juventino V., "Ideas generales sobre la Suprema Corte como Tribunal Constitucional", en el colectivo La justicia mexicana hacia el siglo XXI, UNAM/Senado de la República (LVI Legislatura), México, pág. 71; Rodríguez Lozano, Amador, "La reforma judicial de 1994: una visión integral", en el colectivo La justicia mexicana ..., cit., pág. 50-51.

5. Son varios los elementos que han llevado a la doctrina mexicana a considerar a su Suprema Corte, tras las últimas reformas constitucionales, un verdadero tribunal constitucional: sus propias competencias (acción de inconstitucionalidad y controversias constitucionales, tanto las interorgánicas como las competenciales); la reducción sustancial de su composición numérica, pues el Pleno pasa a integrarse por once magistrados; el sistema de designación de los Magistrados (llamados Ministros) por autoridades políticas, así como su renovación escalonada en el tiempo; la independencia y autonomía, presupuestaria y organizativa, garantizadas al Tribunal; y, en fin, su progresiva especialización en materia constitucional.

Por nuestra parte, aún cuando pensamos que no puede afirmarse en rigor que la Suprema Corte sea un verdadero tribunal constitucional por ser ésta una evolución todavía no completamente ultimada por cuanto dicho Tribunal retiene ciertas competencias de mera legalidad ordinaria cuya atribución a un auténtico tribunal constitucional no puede justificarse (recursos de apelación y de revisión; unificación de doctrina; conflictos jurisdiccionales, etc.), lo cierto es que materialmente se aproxima a uno de estos tribunales y, desde luego, aunque no sin notables limitaciones, se halla más próxima en la actualidad de ser uno de ellos que de ser lo que su nomen iuris parece continuar indicando, es decir, un tribunal de naturaleza casacional.

6. Francisco Fernández Segado, La jurisdicción constitucional en la actualidad, Ius et Praxis, Facultad de Derecho y Ciencias Políticas de la Universidad de Lima, núm. 16, diciembre 1990 , pág. 77.

7. Los diputados y senadores pueden impugnar leyes federales o del Distrito Federal expedidas por el Congreso de la Unión, pero los senadores también los Tratados Internacionales. Los parlamentarios estatales o de la Asamblea de Representantes del Distrito Federal pueden impugnar solamente las leyes aprobadas por el órgano legislativo al que pertenezcan.

8. En Alemania, la doctrina suele coincidir en señalar cómo, de este modo, cumple el Tribunal una importante función de protección de la minoría parlamentaria (eine wichtige Funktion zum Schutz der parlamentarischen Minderheit). Horst Säcker, Das Bundesverfassungsgericht: Status, Funktion, Rechtsprechungs-beispiele, C.H. Beck, Munich, 1975, pág. 34; Sabine Stuth, Verfahren in den Fällen des §13 Nr. 6 (Abstraktes Normenkontrollverfahren, en el colectivo Dieter C. Umbach y Thomas Clemens (coords.), Bundesverfassungs-gerichtsgesetz. Mitarbeiterkommentar und Handbuch, con prólogo de Roman Herzog y Ernst-W. Böckenförde, Heidelberg, C.F.Müller, 1992, pág.976. En el caso de México, la limitación del objeto de la impugnación por las minorías a las normas en que la propia Cámara legislativa a la que pertenecen ha intervenido no hace sino realzar esa función de protección de las minorías, aunque sea, al mismo tiempo, instrumentalizándolas, como en el texto a continuación decimos. Por otro lado, destaquemos que en Alemania, en cambio, bien es cierto que con relación a los Gobiernos de los Länder (y no a las minorías parlamentarias de los mismos), el Tribunal Constitucional, ha entendido que aqué- 
Notas los pueden impugnar no sólo las leyes del propio Land, sino también las de otros Länder y ello sobre la base de que el proceso de control normativo abstracto es un proceso objetivo para la protección de la Constitución, independientemente de los derechos subjetivos, que sirve para el examen de las normas jurídicas según el parámetro de la Ley Fundamental (BVerfGE 83, 49). En España, en cambio, la legitimación de los órganos superiores de las Comunidades Autónomas se limitó a las normas del Estado que puedan afectar a su propio ámbito de autonomía por la LOTC. Sobre ello, véase STC 25/1981, de 14 de julio, FFJ 3-5 (y voto particular); STC 84/1982, de 23 de diciembre, FJ 1; y STC 199/1987, de 16 de diciembre y STC 28/1991, FJ 1.

9. Ello lo decimos en el sentido de que su legitimación parece responder no sólo a la necesidad de protección de las minorías parlamentarias en todo sistema democrático frente a la imposición del criterio mayoritario por la sola fuerza de los votos y por encima de la propia Constitución, sino que también parece obedecer a la circunstancia de que son justamente las minorías parlamentarias las que, al no ver triunfar sus tesis legislativas, han de tener una especial diligencia, por no decir predisposición en ocasiones, para detectar cualquier infracción por vía legislativa de los mandatos constitucionales. De este modo, a través de la legitimación contemplada, no sólo se protegen los intereses legítimos de esas minorías sino que también, al unísono, y no como efecto meramente reflejo sino más bien como objetivo principalmente buscado, se protege la propia supremacía normativa de la Carta Magna, objetivo para el cual precisamente se instrumentaliza a las minorías parlamentarias. Y aunque ello pueda conllevar abusos en ciertos casos, son mayores, a nuestro juicio, los beneficios que de una legitimación de este tipo se derivan y así parece acreditarlo tanto la experiencia española como la de otros países.

10. Una legitimación de este tipo existe, por citar sólo algunos países europeos, en Alemania, Austria, Francia, Rumanía, Portugal y España (en Italia se discute sobre la oportunidad de su introducción). Y entre los países que han acogido una legitimación de este tipo, sólo en los últimos cinco años, pueden mencionarse (entre paréntesis cito la fracción parlamentaria a que se otorga legitimación, así como el año en que se introdujo ésta): Eslovaquia $(1 / 5,1992)$, Eslovenia $(1 / 3,1994)$, Lituania $(1 / 5$, 1992), Bolivia (cualquier diputado o senador, 1994) y Perú $(1 / 4,1993)$.

11. Giustino D'Orazio, "Aspectos y problemas de la justicia constitucional italiana", Revista Vasca de Administración Pública, № 31, septiembre-diciembre 1991, pág. 61.

12. Hans Kelsen, "La garanzia giurisdizionale della costituzione (La giustizia costituzionale)", en su libro recopilatorio La giustizia costituzionale, Giuffrè Editore, Milano, 1981, pág. 202.

13. Debe tenerse presente, en efecto, que al día de hoy, en la actual composición de las Cámaras, la mentada exigencia de un tercio de los representantes (para impugnar una ley aprobada por el órgano legislativo al que pertenezcan) exige que para plantear ante la Suprema Corte la constitucionalidad de una ley por medio de la acción de inconstitucionalidad, se logre en la Cámara de Diputados, un acuerdo de los dos partidos de la oposición más fuertes, pues sólo estos dos partidos opositores unidos (PRD y PAN) pueden reunir el porcentaje requerido del 33 por 100 , no bastando en cambio a estos efectos un acuerdo del PRD con el tercer y cuarto partidos de la oposición en cuanto a representación parlamentaria (PT y Grupo Verde). Y en el Senado, hasta las recientes elecciones de hace apenas unos meses no era posible esa impugnación, pues todas las fuerzas de oposición juntas (PAN, PRD y PT) no reunían más que el 25,7 por 100 de la representación de la Cámara, frente al 33 por 100 requerido. En la actualidad, en el Senado se haría necesario igualmente un acuerdo entre las dos principales fuerzas parlamentarias opositoras (no mayoritarias) para plantear una acción de inconstitucionalidad. Todo ello resulta agravado, si cabe, si se atiende al dato de que las fuerzas parlamentarias entre las que debe lograrse el acuerdo representan tendencias ideológicas contrapuestas entre sí (PAN Y PRD), lo que dificulta muy notablemente dicho acuerdo, que ha de venir referido, obviamente, no sólo al planteamiento de la acción, sino también a sus precisos términos (preceptos impugnados y motivación de la impugnación).

14. Aunque es verdad que en Austria o Alemania también se exige que la acción aparezca respaldada por un tercio de los parlamentarios, también lo es que en España, por ejemplo, se legitima a un séptimo de los diputados y a un quinto de los senado- 
res; y en Portugal, por ejemplo, a un décimo de los diputados. Y desde luego, si la situación mexicana ofrece alguna especialidad es justamente la de la escasa fragmentación parlamentaria desde hace ya casi siete décadas, por más que la situación parezca estar cambiando progresivamente, a marchas forzadas.

15. Hay un dato que resulta por lo demás enormemente significativo de la disfuncionalidad de esta legitimación por el elevado porcentaje establecido: puede darse el caso de que ese porcentaje del $33 \%$ represente un porcentaje mayor que aquel con el que se aprobó (o, en todo caso, podría haberse aprobado) la ley impugnada, puesto que el quórum exigido para quedar válidamente constituidas las Cámaras es de las dos terceras partes en la de Senadores y de la mitad más uno, simplemente, en la de Diputados. Parece que, en tal supuesto, el exceso del porcentaje requerido es tan obvio como absurdo el resultado al que conduce: para impugnar una ley se requiere una mayoría superior a la precisada para aprobarla y, por consiguiente, también a la necesaria para derogarla. Podría resultar más difícil, en tales supuestos, a una fuerza o fuerzas parlamentarias impugnar una ley presuntamente inconstitucional que derogarla lisa y llanamente, en cuanto que se necesitaría en el primer caso el consenso de mayor número de representantes que en el segundo.

16. En cuanto a la personación en juicio de la minoría parlamentaria como parte demandante se le exige que designe, en la instancia inicial, como representantes comunes a dos o más de sus integrantes, quienes actuarán conjunta o separadamente durante todo el procedimiento y aún después de concluido éste. En caso de que no se designaren representantes comunes, el Presidente de la Suprema Corte lo hará de oficio. Los representantes comunes podrán acreditar delegados para que hagan promociones, concurran a las audiencias y en ellas rindan pruebas y formulen alegatos, así como para que promuevan los incidentes y recursos (artículo 62 LR105). No cabe, pues, la designación de representante a persona que no integre la minoría parlamentaria que ejerce la acción, como tampoco es posible la delegación de la legitimación, pues los delegados de que habla la ley o son de los representantes, a los efectos señalados. En todo caso, se presumirá que quienes comparezcan a juicio gozan de la representación legal y cuentan con la capacidad para hacerlo, salvo prueba en contrario (artículo 11 LR105). La Ley Reglamentaria, dadas las peculiaridades de los procesos constitucionales, no admite el sobreseimiento por desestimiento del actor, con lo cual, una vez presentada la acción de inconstitucionalidad, no es posible sustraer a la Suprema Corte del conocimiento de la cuestión.

17. Por lo que a la personación en juicio del Procurador General se refiere, debe señalarse que el artículo 102 constitucional establece que intervendrá personalmente en todo lo referido al ejercicio de las acciones de inconstitucionalidad y no, por consiguiente, por conducto de sus inferiores jerárquicos o cualesquiera otros representantes; la propia Ley Orgánica de la Procuraduría General de la República reitera esta idea al señalar que la interposición de la acción de inconstitucionalidad es función personal e indelegable del Procurador General.

18. Como dijera Ortega, la salud de las democracias, cualquiera que sea su tipo y grado, depende de un mísero detalle técnico: el procedimiento electoral. Todo lo demás es secundario. José Ortega y Gasset, La rebelión de las masas, Espasa Calpe, Madrid, 1964 (primera edición en 1937).

19. La legitimación específica de los partidos políticos no se concibe, en efecto, como una legitimación excluyente del régimen común que existe para todas las leyes, sino que es una legitimación cumulativa de la reconocida en favor del Procurador General y de las minorías parlamentarias: a esa legitimación general para todo tipo de leyes se añade ahora otra específica para las leyes de carácter electoral, lo cual supone, por lo demás, una cierta intensificación del control de las leyes electorales por la vía de la acción de inconstitucionalidad. Ahora bien, paralelamente a esa intensificación del control por la vía de la acción de inconstitucionalidad de las leyes electorales, se ha consagrado una norma en virtud de la cual la única vía para plantear la no conformidad de las leyes electorales a la Constitución es la prevista en este artículo (artículo 105.II de la Constitución), esto es, la iniciada por la acción de inconstitucionalidad. Se excluye, así pues, y de manera que no deja lugar a dudas, el control de constitucionalidad de las leyes electorales a través tanto de las controversias constitucionales _sobre las que el mismo precepto, en su apartado I, establece que no pueden extenderse nunca a la materia electoral_ como por la vía del amparo contra leyes, a diferencia de lo que ocurre con las demás leyes, peculiari- 
dad que si bien podría quizás admitirse respecto de la exclusión de la impugnación de estas leyes por vía del amparo, no parece que sea igualmente justificable respecto de las controversias constitucionales. Supone además que transcurrido el fugaz plazo legal de tres meses desde la publicación de la ley para plantear una acción de inconstitucionalidad, no es posible activar mecanismo alguno para el control de la constitucionalidad de las leyes electorales, lo que no parece en modo alguno acertado.

20. Aunque el partido de que se trate sí que ha de tener, obviamente, un apoyo social o militancia mínimos en cuanto que ha de ser un partido legalmente registrado y el artículo 24 del Código Federal de Instituciones y Procedimientos Electorales (COFIPE) exige para el registro de una organización como partido político, que cuente con 3000 afiliados en por lo menos diez entidades federativas o 300 afiliados en por lo menos 100 distritos electorales uninominales, sin que en ningún caso el número total de sus afiliados en el país pueda ser inferior al 0.13 del padrón electoral federal utilizado en las elecciones federales inmediatamente anteriores.

La legitimación contemplada respecto de las minorías parlamentarias, en cambio exige el acuerdo de al menos un 33 por ciento de los integrantes del órgano legislativo que expidió la ley, quienes normalmente pertenecerán a un mismo partido o a dos partidos opositores, con lo que implícitamente se exige que el partido o partidos impugnadores (que son quienes están realmente detrás de los parlamentarios) tengan por sí o conjuntamente una determinada, y nada pequeña por cierto representación parlamentaria, sea a nivel federal o estatal. Nada de ello funciona, en cambio, con relación a la legitimación de los partidos políticos frente a las leyes electorales.

21. La Suprema Corte ha entendido que si el partido promovente [de la acción de inconstitucionalidad] demuestra haber solicitado el registro condicionado [ante el Instituto Federal Electoral, o ante el registro estatal, según sea un partido de ámbito federal o local] conforme a la convocatoria expedida por la autoridad electoral y ésta le negó el registro, debe estimarse que carece de legitimación procesal para ejercitar la acción constitucional de mérito por no acreditar contar con el certificado respectivo, expedido en términos de lo dispuesto por los artículos 22 y 23 COFIPE (Acción de inconstitucionalidad 7/96, de 7 de enero; tesis 16/1997, de 10 de febrero). Para el registro definitivo de un partido político, aparte de la necesaria militancia mínima aludida ya en la nota anterior, se exige que la organización que pretenda el registro formule, con el contenido mínimo previsto en los artículos 25 a 27 COFIPE, una declaración de principios, un programa de acción y unos Estatutos (artículo 24 COFIPE). Cfr., también, los artículos 28 a 31COFIPE.

Por otra parte, el artículo 32 COFIPE establece que al partido que no obtenga por lo menos el dos por ciento de los votos en alguna de las elecciones federales ordinarias para Diputados, Senadores o Presidente de la República le será cancelado el registro y perderá todos sus derechos y prerrogativas, sin que pueda solicitar de nuevo el registro hasta después de transcurrido un proceso electoral federal ordinario.

22. Así, por ejemplo, en el caso del Partido Revolucionario Institucional sus estatutos atribuyen la competencia para plantear la acción de inconstitucionalidad, de entre sus órganos directivos, al Presidente del Comité Ejecutivo Nacional (artículo 83.XIX). En cuanto al Partido de Acción Nacional, la Suprema Corte declaró improcedente la acción de inconstitucionalidad 5/96 por haber sido planteada dicha acción por su Secretario General y no, como correspondería, por su Presidente.

23. Se trata de una solución prudente y comprensible, en cuanto que no hay un cambio de régimen ni de texto constitucional, como sí lo hubo en Italia con la Constitución de 1947, en Alemania con la Ley Fundamental de 1949 o en España con la Constitución de 1978.

24. Y en particular se referirá este control de constitucionalidad al respeto de las bases generales que respecto de la organización político-constitucional de los Estados se establecen en la Constitución Federal.

25. Sobre la distinción entre límites expresos, inmanentes e implícitos a la reforma constitucional, puede verse Marie-Françoise Rigaux, La théorie des limites matérielles à l'exercice de la fonction contituante, Ferdinand Larcier, Bruselas, 1985, pág. 204; véase también José Joaquim Gomes Canotilho, Direito Constitucional, Almedina, Coimbra, 1993 pág. 1129 y ss. 
Notas 26. Sobre la cuestión, me remito al estudio de síntesis de Salvador Valencia Carmona, Derecho Constitucional mexicano a fin de siglo, Porrúa, México, 1995, pág. 43-44.

27. En cualquier caso, aún en la hipótesis de admitirse la existencia de esa clase de límites, es innecesario señalar que un control de este tipo es únicamente imaginable en situaciones constitucionales patológicas de gravedad en las que, probablemente, la Justicia Constitucional ya poco pueda aportar, por sí misma, para hacer realmente operativos esos límites.

28. La presente Constitución puede ser adicionada o reformada. Para que las adiciones o reformas lleguen a ser parte de la misma, se requiere que el Congreso de la Unión, por el voto de las dos terceras partes de los individuos presentes. Acuerde las reformas o adiciones, y que éstas sean aprobadas por la mayoría de las legislaturas de los Estados. El Congreso de la Unión o la Comisión Permanente hará el cómputo de los votos de las legislaturas y la declaración de haber sido aprobadas las adiciones o reformas.

29. Y, naturalmente, todavía menos se acepta el control material al que nos hemos referido antes.

30. Elisur Arteaga Nava, La controversia constitucional ..., cit., p. 53. Madrazo, por su parte, señala: por último, y en relación con la posibilidad de que el Poder Judicial pueda apreciar probables vicios en la tramitación de una reforma constitucional, es incontestable que en el estado actual de nuestro ordenamiento jurídico tal posibilidad es inexistente, pues para ello sería necesario que así lo declarase la propia Constitución, sumando al poder revisor de la Constitución el órgano y la instancia judicial, lo que en la especie no sucede [...] Sólo una interpretación errónea e interesada podría colocar al Poder Judicial Federal, en tanto que poder constituido, por encima del poder revisor o constituyente permanente. Jorge Madrazo, $\mathrm{El}$ artículo 135, en el colectivo Constitución política de los Estados Unidos Mexicanos, comentada, Porrúa/Instituto de Investigaciones Jurídicas de la Universidad Nacional Autónoma de México, tomo II, México, 1995, pág. 1375.

31. Véase, al respecto Ignacio Burgoa, Derecho Constitucional mexicano, Porrúa, México, 1996, pág. 656-657.

32. Pedro de Vega, La reforma constitucional y la problemática del poder constituyente, Tecnos, Madrid, 1985, pág. 296.

33. Sobre éstos, véase Ignacio Burgoa, Derecho Constitucional ..., cit., pág. 783 y ss.

34. Héctor Fix Fierro, La reforma judicial ..., cit., pág. 122.

35. Para Alemania, donde el control se ha instaurado por vía jurisprudencial, véase BVerfE 2,79; BVerfE 1, 396 (pág. 411 y ss.); 4, 157 (pág.162); 12, 205 (pág. 220 y ss.) y Konrad Hesse, Grundzüge des Verfassungsrechts der Bundesrepublik Deutschland, C.F.Müller, Heidelberg-Karlsruhe, 1980 pág. 268, No. 15; para Francia, véase, la Ley $\mathrm{N}^{\circ}$ 92-554 y los artículos 18 y ss. de la LOCC, reformada también por Ley Orgánica 95-63, de 19 de enero de 1995; para Portugal, artículos 278 y 279 Constitución y Título III, Capítulo II, Subcapítulo I, Sección segunda (Processo de fiscalizaçâo preventiva), artículos 57 a 61 LTC; para Colombia, artículo 240, punto 10, de la Constitución; y para Andorra, artículo 98 de la Constitución y Título IV, Capítulo III (Del procediment previ de control de constitutionalitat dels Tractats internacionals) de la LQTC.

36. Es decir, una vez ratificado el Tratado Internacional, no hay forma de destruir ni la vinculación internacional del propio Estado, ni tampoco la consiguiente responsabilidad por incumplimiento, incluso en el caso de que el órgano competente para ello declare inconstitucional tal Tratado, salvo cuando lo haga por motivos de falta de competencia, pues la única excepción que la Convención citada admite respecto de la regla de no invocación de normas internas es la referida a aquellas normas internas que regulen la competencia para celebrar Tratados pero, incluso en tal caso, la violación de dichas normas ha de ser manifiesta y afectar a una norma de importancia fundamental en Derecho interno, estableciendo, por su parte, el artículo $46.2 \mathrm{CV}$ que una obligación es manifiesta sólo si resulta objetivamente evidente para cualquier Estado que proceda en la materia conforme a la práctica usual y de buena fe. Fuera de este caso, y siempre que no se concierte con la otra(s) parte(s) para dar por terminado o suspendido (total o parcialmente) el Tratado o modificarlo en el punto en cuestión, el incumplimiento de un tratado internacional por inconstitucional generará responsabilidad internacional del Estado, al margen ya de cuales sean los efectos o consecuencias que de ello a nivel estrictamente interno puedan derivarse. 
Notas 37. La Constitución no establece en modo alguno tal distinción entre tratados y convenios internacionales como categorías diversas, sino que emplea ambas terminologías como sinónimas; y, en particular, el artículo 89 de la Constitución establece que es competencia del Presidente de la República la celebración de "tratados internacionales", sin que en ningún otro precepto se establezca una competencia distinta para la celebración de esos convenios internacionales pretendidamente diversos de los tratados internacionales. A nivel internacional, toda posibilidad de una distinción de ese tipo queda cerrada o descartada, rotundamente, por la Convención de Viena sobre el Derecho de los Tratados, de 23 de mayo de 1969, la cual se refiere expresamente a esta cuestión terminológica casi en su mismo frontispicio y así, al definir en su artículo 2 al tratado como todo acuerdo internacional celebrado por escrito entre Estados y regido por el Derecho Internacional, ya conste en un instrumento único o en dos o más instrumentos conexos, termina esta definición con la importante precisión de que se entiende por tratado cualquier acuerdo internacional que cumpla esos requisitos cualquiera que sea su denominación particular. A nivel legal, en fin, el artículo 2.I de la Ley sobre Celebración de Tratados Internacionales, de 2 de enero de 1992, establece que, en el ordenamiento jurídico mexicano se entenderá por Tratado Internacional el convenio regido por el Derecho Internacional Público, celebrado por escrito entre el Gobierno de los Estados Unidos Mexicanos y uno o varios sujetos de Derecho Internacional Público, ya sea que para su aplicación se requiera o no la celebración de acuerdos en materias específicas, cualquiera que sea su denominación, mediante el cual los Estados Unidos mexicanos asumen compromisos (cursiva mía).

38. En todo lo no regulado expresamente por la LR 105 , su artículo 1 se remite a lo previsto en el Código Federal de Procedimientos Civiles, que resulta así de aplicación subsidiaria por disposición legal expresa, con lo cual parece no admitirse la ideosincrasia del proceso constitucional defendida por algún sector de la doctrina alemana.

39. La eficacia de estas consideraciones se regula positivamente en el articulo 43 LR105, en los siguientes términos: Las razones contenidas en los considerandos que funden los resolutivos de las sentencias aprobadas por cuando menos ocho votos [ratio decidendi], serán obligatorias para las Salas, tribunales unitarios y colegiados de circuito, juzgados de distrito, tribunales militares, agrarios y judiciales del orden común de los Estados y del Distrito Federal, y administrativos y del trabajo, sean estos federales o locales.

40. En caso de declaración de invalidez de la norma impugnada, los efectos de la sentencia deberán extenderse a todas aquellas normas cuya validez dependa de la propia norma invalidada, precisión esta última del artículo 41.IV LR105 que hay que entender, en rigor, como una quiebra legal del principio de congruencia que exige que exista una exacta correlación entre el petitum de la demanda y el contenido del fallo, pero que en realidad constituye una exigencia ineludible de la propia estructura del proceso de control normativo a fin de salvaguardar la necesaria coherencia del texto legal al que pertenecían los artículos anulados y ello porque lo dispuesto en ese artículo no puede interpretarse como referido a las normas que dependan jerárquicamente de las disposiciones invalidadas sino que se refiere, evidentemente, a todas aquellas normas que dependan lógicamente de la norma que se invalida y ello tanto si son normas legislativas como si son normas reglamentarias. La logica del precepto, que guarda por lo demás correlación con preceptos análogos en todos los sistemas de control concentrado de constitucionalidad, es la de preservar la coherencia del ordenamiento jurídico en su conjunto. Es particularmente necesario, en cualquier caso, que la Suprema Corte establezca claramente cuáles son esos preceptos a los que se extienden los efectos de la sentencia estimatoria, así como también, por otra parte, la fecha a partir de la que las sentencias producirán sus efectos (artículo 45 LR105). 
41. CUADRO DE MAYORÍAS REQUERIDAS PARA QUE PROSPERE LA DECLARACIÓN DE INCONSTITUCIONALIDAD, EN FUNCIÓN DEL NÚMERO DE MINISTROS PRESENTES:

$\begin{array}{ccc}\begin{array}{c}\text { Número de miembros } \\ \text { del Pleno presentes }\end{array} & \begin{array}{c}\text { A favor de la } \\ \text { inconstit. }\end{array} & \begin{array}{c}\text { En contra Mayoría } \\ \text { requerida }\end{array} \\ 11 & 8 & 3 \\ 10 & 8 & 2 \\ 9 & 8 & 1 \\ 8 & 8 & 0\end{array}$

\section{$72,7 \%$ \\ $80,0 \%$ \\ $88,8 \%$ \\ UNANIMIDAD}

42. Paul Kirchhof, Efectividad de los derechos fundamentales; en particular, en relación con el ejercicio del poder legislativo, en el colectivo Antonio López Pina (dir.), La garantía constitucional de los derechos fundamentales. Alemania, España, Francia e Italia, Civitas-Universidad Complutense, Madrid, 1991, pág. 253.

43. Héctor Fix Fierro, La defensa de la constitucionalidad ..., cit., pág. 55, n. 31.

44. Aunque el artículo 19.IV LR 105 exige no sólo identidad de objeto y de causa, sino también de partes, entiendo que ello es así únicamente respecto de las controversias a las que específicamente se dirige el precepto, pero no respecto de las acciones de inconstitucionalidad, a las que se refiere sólo indirectamente, por remisión al mentado precepto del artículo 65 LR105 y que responden a una lógica distinta.

45. Nos referimos a los criterios que hayan constituido la ratio decidendi de una resolución anterior y no a los obiter dicta, que no le vinculan en absoluto.

46. Héctor Fix Fierro, La Reforma Judicial de 1994 y las acciones de inconstitucionalidad, Ars Iuris, Revista del Instituto de Documentación e Investigación Jurídicas de la Facultad de Derecho de la Universidad Panamericana, $N^{\circ} 13$, especial sobre la Reforma Judicial, México, 1995, pág. 123. Esta fórmula, si bien pudo cumplir históricamente una función de importancia, hoy parece que ha de ser de un modo u otro superada, tanto por razones de economía procesal y congruencia jurídica cuanto por razones elementales de igualdad ante la ley, especialmente de aquellos socialmente más debiles y cuyo acceso real a los tribunales está de hecho vedado. No cabe duda, en cualquier caso, que la regulación de la acción de inconstitucionalidad en este punto supone un importante avance en la línea indicada, por más que no resulte todavía suficiente.

48. Son causas de improcedencia: impugnación de normas generales que sean materia de una acción de inconstitucionalidad pendiente de resolver, siempre que exista identidad de partes, normas generales [...] y conceptos de invalidez (litispendencia); impugnación de normas generales que hubieren sido materia de una ejecutoria dictada en otra acción de inconstitucionalidad siempre que exista identidad de partes, normas generales [...] y conceptos de invalidez (cosa juzgada); cesación de los efectos de la norma general impugnada; presentación de la acción una vez transcurrido el plazo de tres meses (extemporaneidad).

49. Son causas de sobreseimiento la prueba de la inexistencia de la norma, así como cualquier causa de improcedencia que sobrevenga durante el juicio. Ello ha sido interpretado por la Suprema Corte como una exigencia de que el juzgador, con la mera lectura del escrito inicial y de sus anexos, considera probada la correspondiente causa de improcedencia sin lugar a dudas, sea porque los hechos sobre los que descansa hayan sido manifestados claramente por el demandante o porque estén probados con elementos de juicio indubitables, de suerte tal que los actos posteriores del procedimiento no sean necesarios para configurarla en forma acabada y tampoco puedan, previsiblemente, desvirtuar su contenido.Tesis LXXII/95 $\left(9^{2}\right)$, emitida en el recurso de reclamación de la acción de inconstitucionalidad 1/95. 